\title{
Summary Report Documenting Status of the Rare Earth Oxide Investigation
}

\author{
Theodore M. Besmann, Stewart L. Voit, and Dongwon Shin \\ Oak Ridge National Laboratory
}

April 30, 2010

The goal of this work is to enhance the understanding of ceramic nuclear fuel thermochemistry through a coordinated modeling and experimental approach. This work supports the Advanced Fuels Campaign Feedstock and Fabrication Technology R\&D Program and is focused on the following tasks: (1) use existing compound energy formalism-based models to support Los Alamos National Laboratory (LANL) fuel development activities, (2) assess rare earth (RE) oxide systems and begin development of thermochemical representations of U-RE-O systems, and (3) develop a U-Ce-O thermochemical model for the fluorite-structure phase.

In support of the experimental efforts at the LANL, an assessment of temperature-oxygen potential conditions for preparing stoichiometric $\mathrm{U}_{1-\mathrm{y}} \mathrm{Ce}_{\mathrm{y}} \mathrm{O}_{2}$ at relatively low values of y $(<0.4)$ was performed. There is significant agreement in the literature that both the independent urania and ceria phases, and the urania-ceria solution phase are stoichiometric at oxygen-to-metal $(\mathrm{O} / \mathrm{M})$ ratios of 2 at $850^{\circ} \mathrm{C}$ and an oxygen potential of $-368 \mathrm{~kJ} / \mathrm{mol}$. The oxygen potential value is obtained at a partial pressure of $\mathrm{CO} / \mathrm{CO}_{2}$ ratio of unity at 1 bar total pressure. This information was successfully applied in thermogravimetric analysis experimental efforts at LANL investigating urania, ceria, and blended powders of the two oxides.

Data reported in the literature for oxygen potential-temperature-composition for $\mathrm{U}_{1-\mathrm{y}} \mathrm{Ce}_{\mathrm{y}} \mathrm{O}_{2-\mathrm{x}}$ was extracted manually and used to generate a data file. Assessment of the data showed both wide error ranges within sets of data as well as inconsistencies between data sets of different investigators. Figure 1, a plot of the extracted data, illustrates the paucity of experimental data with respect to composition, temperature, and O:M space. For example, as shown in Figure 1, the data as a function of temperature are limited to the range $873 \mathrm{~K}$ to $1273 \mathrm{~K}$ and higher O:M ratios. Furthermore, the compositions studied have focused on higher uranium fractions and very little work has been done at corresponding lower O:M ratios.

A compound energy formalism representation has been developed for the $(\mathrm{U}, \mathrm{Ce}) \mathrm{O}_{2: \mathrm{x}}$ utilizing developed models for the $\mathrm{UO}_{2=\mathrm{x}}$ from Gueneau et al. (2002) and $\mathrm{CeO}_{2-\mathrm{x}}$ of Zinkevich et al. (2006). A three sublattice approach was used to allow for uranium of valences up to +6 . Vacancies are considered only on the anion sites. The ionic species are introduced in the sublattice as follows:

$$
\left(\mathrm{U}^{6+}, \mathrm{U}^{4+}, \mathrm{U}^{3+}, \mathrm{Ce}^{4+}, \mathrm{Ce}^{3+}\right)_{1}\left(\mathrm{O}^{2-}, \mathrm{Va}\right)_{2}\left(\mathrm{O}^{2-}, \mathrm{Va}\right)_{1}
$$

Gibbs free energy expressions for each of the derived constituents can be determined from standard state values. Optimizations using all available thermochemical information, e.g., oxygen potentials and phase equilibria, can thus yield the necessary corrections to the Gibbs free energies for the non-standard constituents and derived interaction parameters ( $L$ values). While a model is available that includes all the interactions separately among the urania and ceria 
species, determination of any possible non-ideal interactions between the urania and ceria cations requires optimization from first principles (if possible) and experimental data for the system.

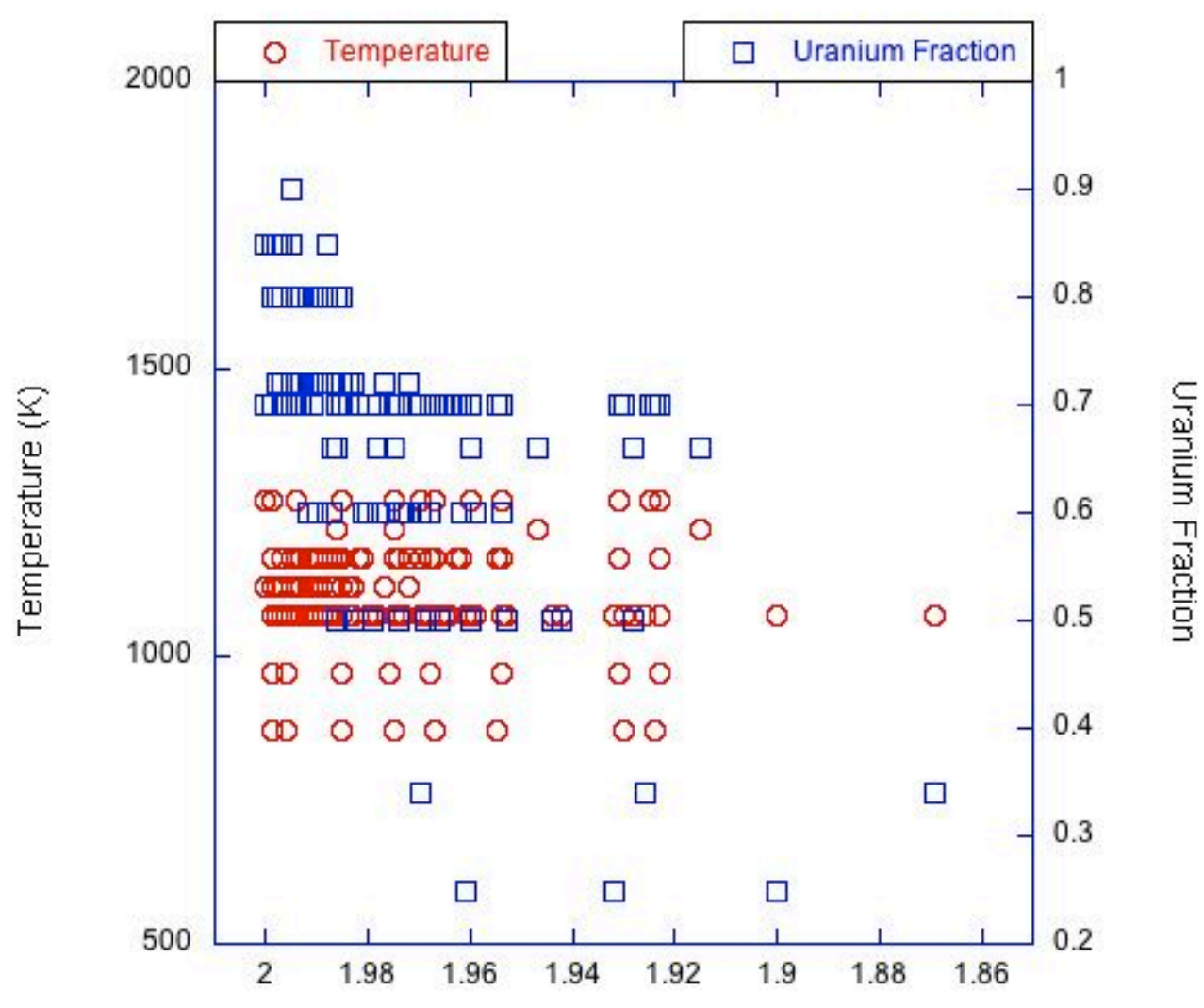

Oxygen to Metal Ratio (O:M)

Fig. 1. Plot of selected data extracted from the literature for $\mathrm{U}_{1-\mathrm{y}} \mathrm{Ce}_{\mathrm{y}} \mathrm{O}_{2-\mathrm{x}}$ showing temperature, O:M ratio, and uranium fraction of the metals uranium and cerium.

Utilizing the best set of data for oxygen potential-temperature-composition for $\mathrm{U}_{1-\mathrm{y}} \mathrm{Ce}_{\mathrm{y}} \mathrm{O}_{2-\mathrm{x}}$ the FactSage thermochemical computational software code was used to optimize the system for selected Gibbs free energy functions and interaction parameters. While it was possible to obtain optimized solutions, the resulting parameters did not allow adequate reproduction of the data, as can be seen in Fig. 2. As noted above, the quality of the data among the various investigators is poor and that is a likely cause for the lack of a reasonable representation.

The focus for the remainder of the fiscal year will be twofold. There will be collaboration with LANL on the collection of experimental data to resolve inconsistencies in the literature data and to fill some of the gaps in the experimental space. Next the thermochemical data will be used to optimize model parameters in an attempt to achieve a better fit to the data, in particular at higher ceria concentrations and at the lower and upper range of O:M. 




Fig. 2. Extracted data (symbols) from Norris and Kay (1983) and Nagarajan et al. (1985) fitted to a compound energy formalism representation (lines).

\section{$\underline{\text { References }}$}

C. Gueneau, M. Baichi, D. Labroche, C. Chatillon and B. Sundman, J. Nucl. Mater., 2002, 304, 161-175.

K. Nagarajan, R. Saha, R. B. Yadav, S. Rajagopalan, K. V. G. Kutty, M. Saibaba. P. R. Vasudeva Rao, and C. K. Mathews, J. Nucl. Mater., 1985, 130, 242-249.

D. B. Norris and P. Kay, J. Nucl. Mater., 1983, 116, 184-194.

M. Zinkevich, D. Djurovic, and F. Aldinger, Solid State Ionics, 2006, 177, 989-1001. 